\title{
Artigos
}

Raíssa Francisco dos Santos ${ }^{1}$ Edna Rodrigues Araujo Rossetto 2

\section{Feminismo, culturas infantis, gênero e raça: uma reflexão sobre ser menina negra}

\begin{abstract}
Resumo: O presente artigo tem como objetivo discutir aspectos referentes aos estudos da produção das culturas infantis, destacar a importância do protagonismo de meninas negras na pré-escola e evidenciar o quanto são afetadas pelas relações sociais racistas e sexistas legitimadas pelo sistema capitalista. O aporte teórico é constituído por estudos de Kimberly Crenshaw(1989), Helena Hirata(2014), Ângela Davis(1982), Lélia Gonzales(1984). Podemos observar a relevância relativa a cada uma dessas categorias, seu sentido e a compreensão de como operam em conjunto. Os estudos de Fernandes (1989) propiciarão a abrangência histórica necessária e a relação classe/raça que contextualiza a relevância de entender as interseccionalidades de tais categorias.
\end{abstract}

Palavras-chave: Pré-escola. Menina Negra. Racismo. Relações de gênero. Culturas Infantis.

\section{Feminism, peer culture, gender and race: a reflection on being a black girl}

\begin{abstract}
The objective of this article is to discuss studies on the production of children's cultures, highlighting the importance of the role of black girls in pre-school and show how affected they are by racist and sexist relationships in pre-school, legitimized by the capitalist system. From the studies of Kimberly Crenshaw (1989), Helena Hirata (2014), Angela Davis (1982), Lélia Gonzales (1984) and Fernandes (1989) we will provide the historical scope for the subject as inter-relations and processes of the interaction between power relations and categories such as class, race, gender and identity. Racial struggle, a class struggle, and gender equality must all come together in the struggle for the transformation of society.
\end{abstract}

Keywords: Pre-school. Black girl. Racism. Gender relationships. Peer culture.

\footnotetext{
1 Graduada em Pedagogia pela Universidade Estadual Paulista Júlio de Mesquita Filho Mestranda no GEPEDISC - Linha Culturas Infantis do PPGE/FE-UNICAMP. E-mail: raissafransantos@gmail.com

2 Doutora em Educação pela Universidade Estadual de Campinas. Membra do GEPEDISC Linha Culturas Infantis do PPGE/FE-
} UNICAMP. COCEU- Coord do CEUs e Educação Integral da Prefeitura Municipal de São Paulo. E-mail: ednarossetto@gmail.com 


\begin{abstract}
"Houve uma época em que não se podia conhecer previamente o sexo dos bebês. Nesse tempo, muitas grávidas rezavam para não dar à luz meninas, já que, para mulheres, a vida só guardava trabalhos, sofrimentos e humilhações. Ansiavam, essas grávidas, por meninos, guerreiros, príncipes da vida pública, e, em casa, recebidos com chinelos macios, jornais e recomendações (aos outros) de silêncio, que o papai trabalhou o dia todo e agora precisa descansar" (Valesca de Assis).
\end{abstract}

o observarmos a formação inicial da classe trabalhadora, geralmente nos reportamos ao
período escravocrata e às grandes lutas realizadas no processo que culminou na abolição. A
estrutura social brasileira é marcada pela transição de uma sociedade escravagista para construção de uma sociedade capitalista. O fim oficial da escravidão (1888), a proclamação da república (1889) e a Constituição Federal (1891) são fatores importantes a serem considerados no processo de formação do Estado Brasileiro, uma vez que tal processo gerou muita desigualdade social no País. Segundo Florestan Fernandes (1989) as desigualdades sociais brasileiras são pautadas na subordinação do sujeito negro e das classes oprimidas existentes no Brasil e os resquícios desse período são históricos. A Fundação Palmares, (2016) em seu Caderno de Cultura Afrobrasileira e Identidade Nacional, afirma que:

Este processo de transição foi marcado pela convivência entre trabalhadores livres e escravizado. Esta convivência ampliou a luta pela abolição, atraindo setores médios da sociedade, setores da classe operária e levando as ideias abolicionistas para o parlamento. Os centros urbanos se constituíram no centro de gravidade do processo de formação da classe trabalhadora no Brasil. Só que, a inserção do povo negro no mercado de trabalho se deu em condições precárias, particularmente nos serviços domésticos, transporte, comércio e portos. (FUNDAÇÃO PALMARES, 2016, p.91.)

Dessa forma a luta pela liberdade do povo negro escravizado é parte do processo da formação da classe trabalhadora no Brasil. No mesmo periódico, encontramos afirmações de que o povo negro das grandes cidades, bem como do interior do Brasil, passou a enfrentar problemas estruturais como a pobreza, a imposição de baixos salários e a discriminação racial. Funda integração do povo negro no mercado de trabalho da sociedade de classes capitalista foi marcada pela super exploração da força de trabalho, piores empregos e piores salários. (FUNDAÇÃO PALMARES, 2016, p.91). Esta situação perdura até hoje e é certamente uma herança colonial. Entendemos, a partir do contexto histórico exposto, que a situação da mulher negra no Brasil manifesta um prolongamento da realidade vivida no período colonial com poucas mudanças, pois continua a mulher em último lugar na escala social, sendo a que mais carrega as desvantagens do sistema injusto e racista do país, mais que os homens negros.

É com essas reflexões e sensibilidades que apresentamos nesse artigo alguns aspectos referentes aos estudos da produção das culturas infantis, destacando a importância do protagonismo de meninas negras na pré-escola e evidenciando o quanto são afetadas pelas relações sociais racistas e sexistas legitimadas pelo sistema capitalista. A pesquisa está sendo realizada no município de Hortolândia - SP em 
uma instituição pública de educação infantil em um bairro carregado pelo estigma de abrigar a Complexa Penitenciária Campinas-Hortolândia ${ }^{3}$. No decorrer do artigo faremos alguns apontamentos e princípios de análises de situações colhidas em campo. Sempre com a intenção de sobrepor as opressões em um movimento de interseccionalidade.

\section{A menina negra e as culturas infantis - $O$ pertencimento, a identidade e a resistência}

A situação exposta acima está embebida no resultado de uma ideologia de dominação masculina que é produzida e reproduzida tanto por homens como por mulheres. E é aí que mora o sucesso das opressões estruturais. A pesquisa etnográfica em andamento nos apresenta, em certo momento, uma conversa com duas meninas, Maju (menina branca) e Monifa (menina negra) ${ }^{4}$ :

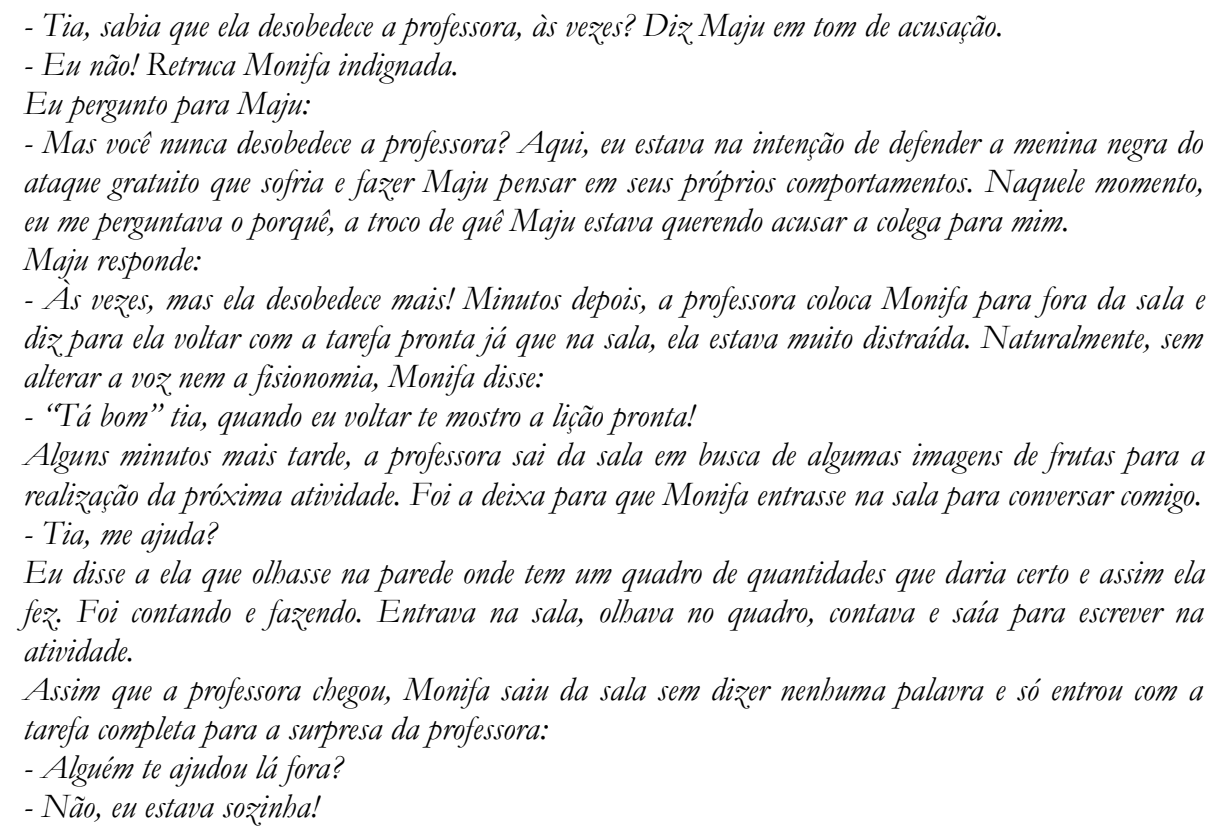

(Fragmento do caderno de campo)

Podemos ver com esse episódio que a menina branca agiu com naturalidade ao acusar a colega negra para mim. Mesmo sabendo que ela também desobedece às vezes, pior era quando sua colega negra desobedecia, isso sim era digno de sanção para a garotinha. Destaco também a surpresa da professora diante da completude da tarefa da menina negra. Monifa não fala muito, no geral, as meninas negras da turma não falam muito. Estão sempre mais quietas em relação ás demais crianças. Repare que Monifa passou por tudo isso quieta e sem alterar o humor.

Inspirada por Chauí (1985), aproximo à análise desse diálogo o patriarcado e racismo com a intenção de mostrar que essas duas opressões têm a mesma raiz, porque é através da violência que uma ação se transforma em diferentes desigualdades hierárquicas com o fim de dominar, explorar e oprimir. A

3 Essa pesquisa está sendo realizada com uma das turmas do Jardim II (4-5 anos). Essa pesquisa teve seu início em 2016.

4 Ambas com 5 anos de idade. 
ação violenta trata o ser dominado como "objeto" e não como "sujeito", o qual é silenciado e se torna dependente e passivo. Nesse sentido, o ser dominado perde sua autonomia, ou seja, sua liberdade, entendida como "capacidade de autodeterminação para pensar, querer, sentir e agir". Seguindo essa concepção, as opressões de gênero e raça se dão separadamente por uma ideologia que define superioridade dos homens sobre as mulheres e dos/as não negros/as sobre os/as negros/as. Posso dizer, então, que Maju esperava garantir seus privilégios por entender que é superior. Talvez ainda não consiga exprimir com palavras o porquê entende assim, mas Monifa sabe que a cor da pele dela faz com que a tratem de maneira diferente.

Quando falo de gênero, falo de relações sociais desiguais de poder entre homens e mulheres, que são o resultado de uma construção social do papel do homem e da mulher a partir das diferenças sexuais, pois nascemos macho e fêmea como todos os animais mamíferos e construímos o que é ser mulher bem como o que é ser homem nesta sociedade. Me atentarei aqui à discussão do ser mulher, mais especificamente, ser mulher negra. A discussão da masculinidade não estará presente neste artigo.

Louro (1997) diz que nas instituições educacionais há reprodução, mas também produção das concepções de gênero e sexualidade e é aí que a pedagogia descolonizadora tem espaço:

É indispensável que reconheçamos que a escola não apenas reproduz ou reflete as concepções de gênero e sexualidade que circulam na sociedade, mas que ela própria as produz. Podemos estender as análises de Foucault, que demonstraram o quanto as escolas ocidentais se ocuparam de tais questões desde seus primeiros tempos, aos cotidianos escolares atuais, nos quais podemos perceber o quanto e como se está tratando (e constituindo) as sexualidades dos sujeitos (LOURO, 1997, p.81).

Podemos ver na pré-escola, uma (re)produção dos conceitos supracitados no que diz respeito também à discriminação racial. Dito de outro modo, a criança pequena, negra ou não negra, quando chega ao sistema escolar, fica exposta à racialização e consequentemente à sua produção e reprodução; O que se mostra bastante explícito na conversa entre mim, Maju e Monifa. A Educação é parte da sociedade e a (re)produz como tal, ou melhor, compreende a educação como instância dentro da sociedade e exclusivamente ao seu serviço.

Faria (2007) nos fala a respeito da relação entre a educação infantil e a sociedade:

Uma pedagogia da educação infantil que garanta o direito à infância e o direito a melhores condições de vida para todas as crianças (pobres e ricas, brancas, negras e indígenas, meninos e meninas, estrangeiras e brasileiras, portadoras de necessidades especiais, etc.) deve contemplar a gama de interesses da sociedade, das famílias e prioritariamente das crianças, atendendo às especificidades de cada demanda a fim de possibilitar a identidade cultural e o sentimento de pertencimento (...) (FARIA, 2007, p.70)

Nós, profissionais da educação infantil estamos aprendendo a olhar as crianças a partir de si mesmas, ou, segundo as instruções de Qvortrup (1995, p.5), aprendendo a "adotar o ponto de vista das crianças, estudando-as pelo seu próprio mérito". Orienta-se que as instituições de educação infantil devem valorizar a espontaneidade das crianças, tornando-as agentes participantes e parceiras nas decisões educacionais, afinal, as crianças são seres sociais e de direitos superando assim, a perspectiva 
adultocêntrica sobre as meninas e meninos pequenininhos e seus respectivos mundos sociais e culturais, visando dar contornos cada vez mais nítidos à Pedagogia da Educação Infantil, pautada nos estudos de Rocha (1999) e Faria (1999). Contudo, a Pedagogia da Educação Infantil é uma Pedagogia da Diferença, pois não busca anular o outro ou medir todos/as com a mesma régua dando a luz para a professora e a falta de luz ao/à aluno/a, mas sim, o compartilhamento da luz de cada um/a com todos/as ao redor. Boa parte do esforço realizado pelas pesquisas com crianças pequenas tem sido no sentido de aprofundar a compreensão no que diz respeito à infância como categoria social e cultural, configurando as crianças pequenininhas como atores sociais e produtores de culturas infantis, bem como reconhecendo-as como sujeitos portadores de direito, tendo vez e voz nas instituições de educação que para elas foram destinadas.

Estreitando todas estas diferenças e especificidades das crianças pequenininhas para a questão central do trabalho - que é a questão da identidade negra feminina e das opressões a ela agregadas - temos que:

Como em outros processos identitários, a identidade negra se constrói gradativamente, num movimento que envolve inúmeras variáveis, causas e efeitos, desde as primeiras relações estabelecidas no grupo social mais íntimo, no qual os contatos pessoais se estabelecem permeados de sanções e afetividades e onde se elaboram os primeiros ensaios de uma futura visão de mundo. Geralmente este processo se inicia na família e vai criando ramificações e desdobramentos a partir das outras relações que o sujeito estabelece. (GOMES, 2005)

A identidade está intrinsecamente ligada aos processos de socialização, formada a partir da relação entre o eu e os outros. É nas interações sociais que a criança negra observa semelhanças e diferenças entre ela e o grupo social que interage, assim, o outro pode servir de referência ou de oposição. Conforme Demartini (2005),

é impossível pensar na construção da identidade, no processo de socialização da criança 'no ar', no abstrato. Tudo isso deve ser pensado em razão do outro, com quem essas crianças convivem (DEMARTINI, 2005, p. 8).

Assim, as identidades se relacionam com o movimento das negações constantes, seja na sua contradição principal, seja nas demais contradições. Segundo Bogo (2008, p. 37):

As identidades estão presentes nas lutas socais, nas lutas de classes, nas lutas entre 'povos' e na formulação de projetos para a superação do capitalismo. Desse processo, fazem com que, da unidade e luta dos contrários, surgem novas identidades com capacidade de compreenderem e intervirem nos processos das negações futuras. As identidades são constituídas de uma forma ou de outra, elas apresentam expectativa de continuidade histórica ainda a ser realizada (BOGO, 2008, p.37)

O pertencimento, a resistência e a identidade são marcas essenciais na formação dos sujeitos sociais. Os estudos de Bogo (2008, p.59) sobre as identidades apresentam uma reflexão sobre a reconstrução dessas. Ele aponta três identidades que vão ajudar no processo de reconstrução da identidade. São elas: a)_Identidade de Resistência - se forma a partir das lutas e resistência para a sobrevivência dos sujeitos. Ela tem no seu horizonte a construção da identidade de classe, bem como a solução dos problemas imediatos e a transformação das estruturas socais e políticas; b) $\underline{\text { A identidade de }}$ Classe e de projeto - se forma quando há reações concretas de luta para não aceitar passivamente aquilo que está estabelecido pela força da classe dominante. Ela se caracteriza pela experiência já feita e pelas 
perspectivas que se abrem a partir da intervenção do sujeito coletivo na história; c) $\underline{\text { A identidade }}$

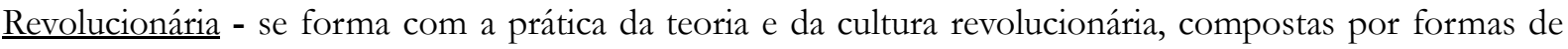
lutas e principalmente pelo pensamento revolucionário. Ela virá na medida em que o movimento das contradições gerais apontarem para a revolução. É o momento em que a classe se amplia se torna consciente e o projeto histórico ao alcance de todos os sujeitos que lutam. O povo, que sempre contou apenas com sua força de trabalho, expressa nas suas lutas a identidade, valores e cultura que se unem à tradição revolucionária. Pátria e nação somente adquirem sentido num projeto de sociedade concebido a partir do processo histórico.

Nesse sentido a identidade da criança negra está em processo de construção e se constitui nas interações sociais, por isso, é fundamental que ela encontre na instituição de educação infantil elementos significativos referentes à sua raça/etnia, de sua cultura etc. A organização dos espaços e das propostas pedagógicas da instituição tem um papel importante no processo de construção da identidade das crianças pequenas. Nas Diretrizes Curriculares Nacionais para a Educação Infantil vemos que:

O reconhecimento, a valorização, o respeito e a interação das crianças com as histórias e as culturas africanas, afro-brasileiras, bem como o combate ao racismo e à discriminação; A pluralidade cultural, isto é, a diversidade de etnias, crenças, costumes, valores etc. que caracterizam a população brasileira marca, também, as instituições de educação infantil. (BRASIL/MEC, 2010, p.21)

Pensar a construção da identidade da menina negra na educação infantil implica, portanto, considerar os aspectos vinculados à forma como o racismo e o sexismo se relacionam e se manifestam na pré-escola e quais seus efeitos sobre essas meninas. Um novo fragmento apresenta essas relações:

Começou a brincadeira com os brinquedos de casa. Como sempre, nem todas as crianças levam brinquedos. A professora propõe que as crianças brinquem de cożinheiras. Ideia aceita! Comę̧am a pegar as boinas (brancas) e os aventais (rosas) para vestir. Avistei um menino branco de boina e fui perguntar se ele precisava de ajuda para amarrar o avental que estava na mão dele. Perguntei:

- Você quer pôr o avental?

- Não, é de mulher!

Pergunto por que o avental é de mulher e ele responde:

- Não... e balança a cabeça.

Em seguida, ele coloca o avental que está segurando no pescoço de um colega também branco e sai correndo. O colega disse:

- Sai fora! Eu não sou mulher e não sou viado!

Os meninos brincam de cozinhar, de comprar na feira, mas de maneira nenhuma vestem o avental cor de rosa. Sem que eu esperasse, um menino negro pediu para que eu colocasse o avental nele:

- Tia, me ajuda?

Levantei e amarrei o avental cor de rosa nele e coloquei a boina em sua cabeça. Todo feliz, deu um sorriso e disse:

- Tia, tira uma foto?

Sem demora, tirei a foto!

(Fragmento do caderno de campo)

Todos os fatos narrados neste trabalho aconteceram na instituição de educação infantil do município de Hortolândia onde é realizada a pesquisa de mestrado de uma das autoras do presente artigo, na turma do Jardim II composta por crianças de 04-05 anos de idade.

A seguir, apresentamos uma cena de um dos primeiros dias de observação. Nestes dias, contemplamos mais do que agimos, porém, tentamos interagir com as crianças. 
- Do quê estão brincando?

- De "mamãe e pap..." "mamãe e filhinho e só!” Responde Monifa (menina negra).

Bia (menina negra), também está brincando de casinha, mas fica sempre rodeando a brincadeira dos meninos. Ela também é geradora de alguns conflitos entre as meninas. Provavelmente, mostrando sua insatisfação em estar ali. Os meninos brincam de carrinho, com animais e peças de montar. E, no meio de tudo um menino negro preparando uma comidinha.

(Fragmento do caderno de campo)

O fato era que Bia (menina negra) estava nitidamente incomodada de estar ali naquela brincadeira e com aquelas crianças. A curiosidade estava ali, ansiosa pra saber como Bia ia sair daquela "enrascada". Ao mesmo tempo, o menino negro parecia estar em paz ali, sozinho com suas panelinhas. Ao menino negro a transgressão, ou seja, a invenção de um papel masculino não ensinado não causava tanto conflito como causava em Bia. Partindo desta perspectiva Finco (2010) trabalha em sua tese de doutorado se referindo às crianças como "transgressoras das fronteiras de gênero" e afirma que as crianças nem sempre vão atender às expectativas ou aos interesses dos adultos e que em suas brincadeiras irão criar novas formas de representar a realidade.

É impossível esquecer que uma das primeiras e mais sólidas aprendizagens de uma menina na escola, consiste em saber que, sempre que a professora disser que "os alunos que acabarem a tarefa podem ir para o recreio" ela deve se sentir incluída. Mas ela está sendo efetivamente incluída ou escondida nessa fala? Provavelmente é impossível avaliar todas as implicações dessa aprendizagem; mas é razoável afirmar que ela é quase sempre duradoura (LOURO, 1997, p.66).

Outro ponto importante nas relações entre as crianças e entre crianças e adultos na educação infantil é a exclusão do feminino na linguagem. Os linguistas defendem que ao se referir no masculino estaremos incluindo a todos, mas de acordo com outros estudiosos (LOURO 1997; MORENO 1999) essa forma de linguagem exclui as mulheres. Portanto, a escolarização e o longo tempo que meninos e meninas "passam" na escola servem também para ensinar-lhes concepções hierárquicas entre os sexos e os papéis que os mesmos devem assumir e assumiram ao longo da história. Em minha observação, foi possível perceber que as brincadeiras das crianças continham traços sexistas. Ao receberem a ordem da professora para brincar no pátio, os meninos logo foram brincar com brinquedos de montar. Quando a brincadeira era no parque, os meninos subiam, desciam, escorregavam, montavam no cavalinho, balançavam no balanço, apostavam corridas, se desafiavam a ultrapassar os obstáculos, isto é, eles "brincavam de brincar". Já as meninas correram para a casinha, rapidamente dividiram tarefas e papéis e logo estavam "brincando de trabalhar". Aproximando ainda mais a lente, pude perceber a diferença dos papéis atribuídos às meninas negras. Como dito anteriormente, uma menina negra repensa ao dizer que brincava de "mamãe e papai”, logo conserta dizendo que está brincando de "mamãe e filhinho e só". Essa mamãe não tem papai, é o que chamamos de mãe solo a antiga "mãe solteira". No mesmo momento, a mamãe branca tem papai, mas não tem filhos, conforme o fragmento:

\footnotetext{
Uma menina branca está brincando com uma boneca, uma Barbie e eu pergunto:

- Do que você está brincando?

- De mamãe e filhinbo. Responde ela.

- E quem é a mamãe?

A menina me mostra a Barbie como resposta.

- E eu sou o pai! Diz. um menino branco que estava à frente da menina com um boneco do Batman na mão.
} 
A partir do momento que admitimos esse papel que o sistema educacional se encarrega de desempenhar podemos pensar de uma forma crítica sobre as questões que abarcam a escolarização e como professoras/es pensarmos, também, em maneiras de intervenção visando modificar esta realidade.

\section{Considerações finais}

As desigualdades estão ligadas às relações de produção e a consciência de grupo à posição ocupada na esfera econômica (burgueses X proletários). Nesse sentido, as lutas se dão no âmbito da classe operária em busca de melhores condições de trabalho, culminando nos países centrais, no desenvolvimento do Estado de Bem-Estar Social. Santos (1999), fala de grupos transclassiais - negros e mulheres, por exemplo - mostrando que existem certas hierarquias que se combinam à classe social. Para Florestan Fernandes (1989, p.61):

Se a classe tem de ser forçosamente o componente hegemônico, nem por isso a raça
atua como um dinamismo coletivo secundário. A lógica política que resulta de tal solo
histórico é complexa. A fórmula "proletários de todo o mundo, uni-vos" não exclui
ninguém, nem em termos de nacionalidades nem em termos de etnias ou de raças.
Contudo, uma é a dinâmica de uma estratégia fundada estritamente na situação de
interesses exclusivamente de classe; outra é a dinâmica na qual o horizonte mais largo
estabelece uma síntese que comporte todos os interesses, valores e aspirações que
componham o concreto como uma "unidade no diverso". Classe e raça se fortalecem
reciprocamente e combinam forças centrífugas à ordem existente, que só podem se
recompor em uma unidade mais complexa, uma sociedade nova.

É importante que a classe social defina seus objetivos, suas estratégias, tendo em vista a composição multirracial das populações em que formam a classe dos trabalhadores. Ainda sob os aportes teóricos de Florestan Fernandes (1989, p.61), "todos os trabalhadores possuem as mesmas exigências diante do capital. Todavia, há um acréscimo: existem trabalhadores que possuem exigências diferenciais, e é importante que encontrem espaço dentro das reivindicações de classe e das lutas de classes.” É importante salientar que o referido autor, em uma sociedade multirracial, na qual a morfologia da sociedade de classes ainda não fundiu todas as diferenças existentes entre os trabalhadores/as, a raça também é um fator revolucionário específico. Por isso, existem duas polaridades, que não se contrapõem, mas se interpenetram como elementos explosivos - a classe e a raça.

Assim, esse dilema liga entre si luta de classes e luta de raças (uma não esgota a outra e, tampouco, uma não se esgota na outra). Para Fernandes (1989) a pessoa negra adquiriu uma situação de classe proletária, no entanto continua a ser sujeito negro e a sofrer discriminações e violências. Afirmar-se somente pela raça pressupõe uma utopia. A resistência negra nas décadas de 30, 40 e parte de 50 suscitou o reacionarismo das classes dominantes, que logo denunciaram o "racismo negro"! Segundo Florestan Fernandes (1989, p. 62): 
Nas lutas de classe dentro da ordem, a solidariedade de classe não pode deixar frestas. As greves e outras modalidades de conflito, que visam o padrão de vida e as condições de solidariedade para o trabalhador, não podem admitir a reprodução das desigualdades e formas de opressão que transcendem à classe (FERNANDES, 1989, P.62).

Consoante a Fernandes, acreditamos que não podemos eliminar a raça, não podemos eliminar a classe e acrescentamos também que não podemos eliminar o gênero em seus papéis sociais do que é ser homem e mulher e suas devidas atribuições e valores na sociedade (...) Elas são fermentos revolucionários tremendos na sociedade brasileira, (...) na medida em que a luta racial atravessar a luta de classes e a igualdade de gênero. Enfim, a luta racial tem de caminhar junto com a luta de classe, na transformação da sociedade englobando a luta do feminismo interseccional ${ }^{5}$. Essa não é uma tarefa exclusiva das pessoas negras. Ela pertence a todos/as nós.

No final da década de 1990, no âmbito internacional, emergem categorias que atendem a variedade de diferenciações que se mesclam com gênero e classe social. São as categorias de articulação e as interseccionalidades. Algumas autoras se apropriam desses conceitos (McKlintock, 1995; Crenshaw, 1989).

Nos estudos sobre interseccionalidade, temos então, teóricas como Kimberly Crenshaw (1989), Helena Hirata (2014), Ângela Davis (1982), Lélia Gonzáles (1982), dentre outras, que observam a relevância relativa a cada uma dessas variáveis, seu sentido e a compreensão de como operam em conjunto. Assume-se então, uma ferramenta teórico-metodológica fundamental para ativistas e teóricas feministas, comprometidas com análises que desvelam os processos de interação entre relações de poder e categorias como classe, gênero e raça.

Mesmo sem nomear teoricamente, Davis (1982) e Gonzáles (1982) desenvolveram conceitualmente as perspectivas que, posteriormente, seriam apresentadas pelo conceito da interseccionalidade, desenvolvido por Kimberlé Crenshaw, primeira a usar o termo 'interseccionalidade' em 1989, para designar a interdependência das relações de poder, de raça, sexo e classe. Em seu trabalho, Crenshaw discutiu o feminismo negro, que argumenta que a experiência de ser uma mulher negra não pode ser entendida em termos de ser negro e de ser uma mulher como formas independentes, mas deve incluir as interações, que frequentemente se reforçam mutuamente. O feminismo, em seu núcleo, é um movimento para abolir as desigualdades que as mulheres enfrentam uma vez que:

A interseccionalidade remete a uma teoria transdisciplinar que visa apreender a complexidade das identidades e das desigualdades sociais por intermédio de um enfoque integrado. Ela refuta o enclausuramento e a hierarquização dos grandes eixos da diferenciação social que são as categorias de sexo/gênero, classe, raça, etnicidade idade, deficiência e orientação sexual. O enfoque interseccional vai além do simples reconhecimento da multiplicidade dos sistemas de opressão que opera a partir dessas categorias e postula sua interação na produção e na reprodução das desigualdades sociais (BILGE, 2009, p. 70).

5 O Feminismo Interseccional é de extrema relevância atualmente porque auxilia na organização das pautas das mulheres negras levando em consideração as suas reais necessidades, já que sofremos uma tripla opressão: racismo, machismo e preconceito de classe. 
Perante essa reprodução a qual o sistema se submete, precisamos revelar às nossas meninas negras, desde a Educação Infantil, que seus lugares sociais não estão determinados. Em Faria (1999), podemos ver como as crianças pequenininhas recusam o racismo. As crianças negras nos mostram sua insatisfação através dos gestos, movimentos, emoções, choros, silêncios, olhares, linguagens verbal e não verbal, mesmo na mais tenra infância, estabelecem trocas simbólicas com seus pares, bem como com os adultos, através de uma rede complexa de linguagem (FARIA, 1999).

Nesse sentido, resistir é criar vida; é não se calar como todos desejam, preferindo o silêncio; é brincar durante o castigo atrás da porta; é poder ter a sensação de estar livre por algum tempo, enquanto lhe colocam em outra sala; é poder... é poder criar... (SANTIAGO, 2014 p.89). Mas podemos encontrar em nossas instituições de educação infantil uma pedagogia que proporcione a construção de uma identidade de resistência? A identidade de resistência pode ser associada a apropriação de traços físicos valorização dos fenótipos específicos da raça negra (nariz largo, cabelo crespo, lábios grossos...) - ou culturais, que possam ser considerados positivos derrubando estigmas e estereótipos.

A lei 10639/03 dispõe sobre a obrigatoriedade do ensino de História e Cultura Afro-Brasileira nas escolas públicas e privadas, em todos os níveis de ensino, inclusive na Educação Infantil e, cria as Diretrizes Curriculares Nacionais para Educação das Relações Étnico-Raciais. É na educação infantil que as crianças começam a conhecer o próprio corpo, as diferenças e semelhanças entre elas e os colegas do grupo, escolhem com quem brincar e se relacionar na escola, bem como quando isso acontece e de que maneira, têm suas preferências por brinquedos e brincadeiras. Portanto, nesse momento, é fundamental uma pedagogia descolonizadora pautada na diferença e, em especial, as relacionadas ao pertencimento racial, não só com as crianças, mas com as famílias e comunidade, como é reafirmado nos documentos produzidos pelo MEC:

O papel da educação infantil é significativo para o desenvolvimento humano, a formação da personalidade, a construção da inteligência e a aprendizagem. Os espaços coletivos educacionais, nos primeiros anos de vida, são espaços privilegiados para promover a eliminação de qualquer forma de preconceito, racismo e discriminação, fazendo com que as crianças, desde muito pequenas compreendam e se envolvam conscientemente em ações que conheçam, reconheçam e valorizem a importância dos diferentes grupos étnico raciais para a história e cultura brasileiras. (BRASIL, 2003, p. 49)

[...] a questão racial deve ser considerada como eixo fundamental. Essa exigência deve incidir sobre desde as políticas de educação infantil, período em que a discriminação racial entre as crianças e entre estas e os adultos é assimilada de forma estrutural na formação dos sujeitos, até as políticas de educação superior. (BRASIL, 2008, p.12).

A proposta pedagógica das instituições de Educação Infantil deve garantir que elas cumpram plenamente sua função sociopolítica e pedagógica. Ela deverá prever condições para o trabalho coletivo e para a organização de materiais, espaços e tempos que assegurem: o reconhecimento, a valorização, o respeito e a interação das crianças com as histórias e as culturas africanas, afro-brasileiras, bem como o combate ao racismo e à discriminação (BRASIL, 2010, p.21). De acordo com os documentos legais 
alistados enfatizamos a necessidade de maior atenção na educação para relações raciais desde a primeira infância.

A "reprodução interpretativa" de Corsaro (2011) é uma maneira de entender o movimento da criação cultural das crianças. Deste modo, o termo reprodução indica o constrangimento causado às crianças pela estrutura social. Enquanto, a palavra interpretativa nos diz que, para além da reprodução está uma contribuição ativa na produção da cultura. Logo, as crianças não se restringem a reproduzir a sociedade tal como lhes é apresentada, mas são capazes de ir além e recria-la.

A produção de expressões infantis, além de nos mostrar a captura da cultura da sociedade por parte das crianças, nos mostra também, uma cultura produzida em um grupo na relação com seus pares e com os/as adultos/as. Esse movimento, confirma que as crianças são seres históricos, produtores de cultura em condições dadas pela sociedade a que pertencem. (FERNANDES, 1979).

\section{Referências}

ASSIS, Valesca. (2004). Todos os Meses. Porto Alegre: AGE.

BILGE, Sirma. (2009), Théorisations féministes de l'intersectionnalité. Diogène, 1 (225): 70-88.

BOGO, Ademar (2008). Identidade e luta de classes. São Paulo: Expressão Popular.

BRASIL (2005). Diretrizes Curriculares Nacionais para a Educação das Relações Étnicos Raciais e para o Ensino de História e Cultura Afro-Brasileira e Africana. MEC/SECAD.

BRASIL (2017). Lei $\mathbf{n}^{\mathbf{0}}$ 11.645, de 10 de março de 2008. Altera a Lei $\mathrm{n}^{\circ} 9.394$ de 20 de dezembro de 1996. Brasília, 2008. Disponível em: http://www.planalto.gov.br/ccivil_03/_ato20072010/2008/lei/111645.htm. Acesso em: 10 mai.2017.

BRASIL (2017). Ministério da Educação. Resolução $\mathbf{n}^{\mathbf{0}}$ 4, de 13 de julho de 2010. Define diretrizes curriculares nacionais gerais para a Educação Básica. Brasília, 2010. Disponível em: http://portal.mec.gov.br/dmdocuments/rceb004_10.pdf . Acesso em: 10 mai.2017.

CHAUÍ, Marilena (1985). Participando do Debate sobre Mulher e Violência. In: Franchetto, Bruna, Cavalcanti, Maria Laura V. C. e Heilborn, Maria Luiza (org.). Perspectivas Antropológicas da Mulher 4, São Paulo, Zahar Editores.

CRENSHAW, Kimberlé (2002). Documento para o encontro de especialistas em aspectos da discriminação racial relativos ao gênero. Estudos feministas 1, p.171-189. Florianópolis, 2002.

BRASIL. Ministério da Educação. Secretaria de Educação Básica. Diretrizes Curriculares Nacionais 
para a Educação Infantil. Brasília: MEC/SEB, 2010.

DAVIS, Angela. Mulher, Raça e Classe (1982). Disponível em:https://we.riseup.net/assets/165852/mulheres-rac3a7a-e-classe.pdf Acesso em 26 de junho de 2017.

DEMARTINI Zeila de Brito Fabri (2005). Infância, pesquisa com relatos orais, in: FARIA, Ana Lúcia Goulart de; DEMARTINI, Zeila de Brito Fabri; PRADO, Patrícia Dias (Orgs.). Por uma cultura da infância: metodologias de pesquisa com crianças. $2^{a}$ edição, São Paulo: Autores Associados, p. 1-17.

FARIA, Ana Lúcia Goulart (Org.) (2007). O coletivo infantil em creches e pré-escolas: falares e saberes. São Paulo: Cortez.

FARIA, Ana Lúcia Goulart (1999). Educação pré-escolar e cultura. Campinas/SP: Editora da UNICAMP/SP: Cortez.

FINCO, Daniela (2010). Educação Infantil, espaços de confronto e convívio com as diferenças: Análises das interações entre professoras e meninas e meninos que transgridem as fronteiras de gênero. Tese (Doutorado em Educação) - Universidade de São Paulo. Disponível em: http://www.teses.usp.br/teses/disponiveis/48/48134/tde-20042010-135714/ . Acesso em: 28 de Junho de 2017.

FERNANDES, Florestan (1979). As Trocinhas do Bom Retiro: contribuição ao estudo folclórico e sociológico dos grupos infantis. In: FERNANDES, Florestan. Folclore e mudança social na cidade de São Paulo. 2 ed. Petrópolis/RJ: Vozes.

. (1989). Significado do Protesto Negro. São Paulo. Ed.

CULTURA AFROBRASILEIRA E IDENTIDADE NACIONAL. São Paulo: Fundação Palmares, $1^{a}$ edição. Formação de agentes socioculturais com enfoque na cultura afrobrasileira e a formação da identidade nacional, 2016.

GOMES, Nilma Lino (2005). Alguns termos e conceitos presentes no debate sobre relações raciais no Brasil: Uma breve discussão. In: Educação anti-racista: caminhos abertos pela lei Federal n¹0.639/03. Brasília: Ministério da Educação, Secretaria de Educação Continuada, Alfabetização e Diversidade.

GONZALES, Lélia (1984). Racismo e sexismo na cultura brasileira. In: Revista Ciências Sociais Hoje, Anpocs, p. 223-244.

GONZALES, L.; HASENBALG, C. A (1982). Lugar de negro. Rio de Janeiro: Editora Marco Zero. 
HIRATA, Helena (2014). Gênero, classe e raça: interseccionalidade e consubstancialidade das relações sociais. Tempo Social. São Paulo, V.26, n¹, pp.61-74, junho.

LOURO, Guacira Lopes (1997). Gênero, Sexualidade e Educação: Uma perspectiva pós estruturalista. Petrópolis, RJ: Vozes.

McKLINTOCK, Anne (1995). Imperial leather, Race, gender and sexuality in the colonial contest. Routledge.

MORENO, Montserrat (2003). Como se ensina a ser menina: o sexismo na escola. São Paulo: Moderna.

QVORTRUP, Jens (1999). A Infância na Europa: novo campo de pesquisa social. Centro de documentação e informação sobre a criança. Instituto de Estudos da Criança. Universidade do Minho. Tradução de Helena Antunes.

ROCHA, Eloisa A. Candal (1999). A Pesquisa em Educação Infantil no Brasil: trajetória recente e perspectiva de consolidação de uma Pedagogia da Educação Infantil. Florianópolis, Centro de Ciências da Educação, Núcleo de Publicações, 1999.

SANTIAGO, Flávio. "O meu cabelo é assim... igualzinho o da bruxa, todo armado": hierarquização e racialização das criamças pequenininhas negras na educação infantil, 2014. 147f. Dissertação (Mestrado em Educação) - Faculdade de Educação, Universidade de Campinas, Campinas..

SANTOS, Boaventura de Sousa. Pela Mão de Alice: o social e o político na pós-modernidade. 5 ed. São Paulo: Cortez, 1999, pág. 256. 